\title{
Answering the challenges of the New Year - the EAPCI in 2018
}

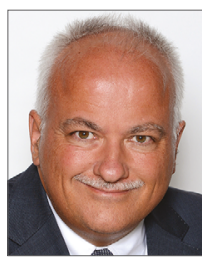

Michael Haude, MD, EAPCI President

Medical Clinic I, Städtische Kliniken Neuss, Lukaskrankenhaus GmbH, Neuss, Germany

At one moment or another we all have the feeling that time moves too quickly. Still, there is no doubting the calendar and, as this is my first column for 2018 , let me first wish you all the very best in the coming year.

Each new year brings with it its own special challenges. Some of these are ones we have not responded to from the previous year, some of these challenges are new and grow out of the evolution in our clinical practice or our respective healthcare systems, while others are linked to the goals we set for ourselves in terms of excellence as we strive to provide the very best care possible today. In facing all these challenges in our professional lives, whatever they are, the European Association of Percutaneous Cardiovascular Interventions (EAPCI) can be a valuable asset. By working together within the structure of a professional association, we can help each other to advance more effectively. As an organisation, we try to respond in the most appropriate, timely and constructive way to the needs of our members, but the value of that response is only as worthwhile and useful as each member's individual participation allows it to be. In short, we need your participation for our association to be truly representative and efficient.

While it seems like only yesterday, it has been almost two years since I assumed the role of President of the EAPCI and now we are approaching new elections. At the time I am writing this column, the names of our candidates are not yet known; however, by the time this edition of EuroIntervention is published, the list of candidates vying to lead the EAPCI into the future will have been announced by our nominating committee. This list can be found on the EAPCI website. The voting period is 1 February 28 February 23:59 CET, and we urge all of you to make a point of voting and taking part in the life of our Association.

In the meantime, you can already plan your upcoming year by marking in your calendars the key EAPCI educational events. EuroPCR 2018, our official flagship course, will be taking place from 22 to 25 May, at our now traditional meeting place, the
Palais des Congrès in Paris, France. Once again, the 2018 Fellows Course will also be taking place at EuroPCR (21 and 22 May 2018). The end of the summer will see our umbrella organisation, the European Society of Cardiology, holding its annual Congress from 25 to 29 August 2018 in Munich, Germany. This year, the ESC Congress will spotlight valvular heart disease. We also invite you to block the dates for EAPCI's own course focusing specifically on transcatheter therapies for valvular heart disease, PCR London Valves 2018 - the Heart Team Course which will take place between 9 and 11 September in London, UK. Remember, for further information you can always consult the EAPCI (www.escardio.org/EAPCI) or EuroIntervention (https://www.pcronline.com/eurointervention/) websites.

Many other changes will make themselves felt as 2018 proceeds. Not the least of these will be the challenge for continued and unbiased education as we begin to fully understand and work with the decision by the professional organisation of our industry partners, EUCOMED, to no longer individually sponsor healthcare professionals. As we have said in earlier columns, we will see how this unfolds over the next few months. It is in dealing with changes like these in which we find yet another reason to strongly believe in the force of our association whose goal is to help us in better understanding and navigating the present, while accomplishing what is necessary for the future.

This coming year will be a great one, constructed using the experience and dedication of individuals who choose to work together, multiplying the force of their skills, talent and knowledge. At this time of year we often hear about how we are at the beginning of a new era, one filled with challenges that can make a difference in our clinical and professional lives. This can be true if each and every one of us chooses to make positive and constructive change happen. The EAPCI and I look forward to accompanying you in this endeavour and wish you all health, happiness and success in your professional and your personal lives. 